doi: https://doi.org/10.15407/dopovidi2018.05.053

УДК 550.4:541.15

\title{
С.В. Кушнір
}

Інститут геології і геохімії горючих копалин НАН України, Львів

E-mail: igggk@mail.lviv.ua

\section{Структурна температура води і утворення морських аерозолів (фізико-хімічний аналіз)}

Представлено академіком НАН Украйни Є.Ф. Ннюковим

Проведено аналіз фізико-хімічних процесів, які зумовлюють утворення морських аерозолів. На підставі нових даних обгрунтовано схему чотиристадійних змін молекулярної структури води під час нагрівання. Для холодних вод деталізовано кластерно-полімерну їх структуру та показано, що інтерфейс на межі з повітрям має значно підвищену структурну температуру, яка переводить його воду із стану I в стан II, характерний для об'ємної води при 100-220 ${ }^{\circ}$ С. Показано, що при барботуванні пасивних газів через розчини солей у воді типу I істотно зростає структурна температура самого розчину, що спричиняє зменшення розчинності газів та підвищення хімічної активності води і розчиненого кисню. Запропоновано нову модель утворення зарядженого кислого аерозолю із негативно заряджених бульбашок повітря.

Ключові слова: структура води, структурна температура, інтерфейс газ/вода, барботажна активачія води, аерозолі.

Морські аерозолі досліджуються давно: спочатку в рамках фізики атмосфери, пізніше - як важлива тема гідрогеохімії та фізичної хімї $[1,2]$. Це прискорило розвиток у галузі структурної хімії води, яка сьогодні стає основою при вивченні хімічних і фізичних процесів у водному середовищі, де завжди проявляють себе специфічні водневі зв’язки між молекулами $\mathrm{H}_{2} \mathrm{O}[3-5]$.

Поняття про структурну температуру води в розчинах ввели у наукову літературу Бернал і Фаулер ще в 1933 р. на підставі подібності ІЧ спектрів води в розчинах і підігрітої до певної температури чистої води. В роботі [6] навіть визначені приблизні структурні температури води в однонормальних розчинах багатьох солей при різних фізичних температурах, але через невизначеність причин самого ефекту ці дані так і не знайшли практичного застосування.

У роботі [4] вперше одержано прямий доказ реального існування підвищеної структурної температури $\left(t_{\text {стр }}\right)$ води в розчині $\mathrm{NaCl}$, що зумовлює помітне зменшення розчинності кисню (це легко фіксується зменшенням Eh) при барботуванні пасивних газів або турбулентному перемішуванні. Отже, підвищення $t_{\text {стр }}$ води є одним із барботажних ефектів

(C) C.В. Кушнір, 2018 


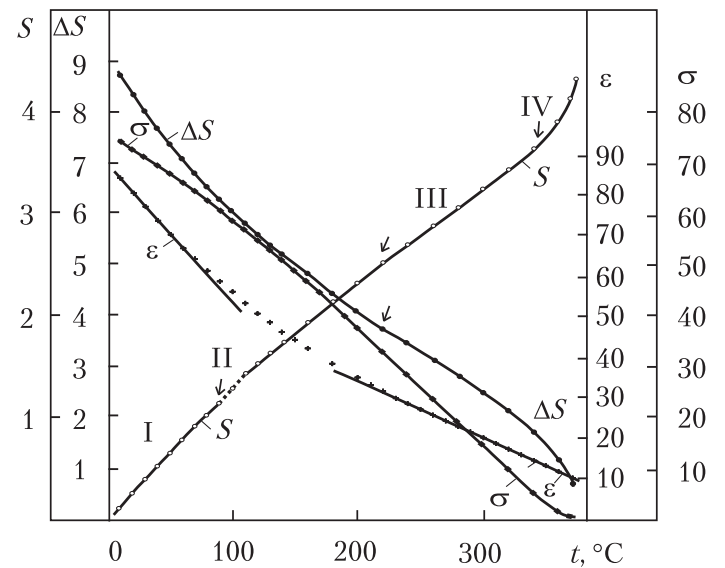

Puc. 1. Зміни структурно-залежних властивостей чистої води під час нагрівання (на лінії насичення). $S$ - питома ентропія, кДж/(кг·К); $\Delta S-$ зміна ентропії пароутворення, кДж/(кг·К); $\varepsilon$ - діелектрична проникність; $\sigma$ - поверхневий натяг, Н/м. Стрілками позначені точки можливих структурних змін

у розчинах і свідчить про певні структурні зміни у незв’язаній іонами частині води розчину.

Загальні зміни структури води під час нагрівання виявлено в результаті порівняльного фізико-хімічного аналізу змін структурно-залежних ï властивостей (рис. 1). Встановлено, що за характером змін питомої ентропії виділяються

чотири етапи, які свідчать про існування чотирьох типів структурної організації рідкої води. Така стадійність пов'язана із зменшенням числа водневих зв'язків (Н-зв'язків) основної маси молекул $\mathrm{H}_{2} \mathrm{O}$ по ряду 3-2-1-нуль. Для кожного із цих чисел зв’язності формуються різні типи структур із різних основних асоціатів, які мають властивості "мерехтливих” кластерів. Основні характеристики цих структурних типів наведені в таблиці.

Отже, чиста вода на Землі може існувати в чотирьох різних структурних типах, які визначаються рівнем їі фізичної температури (і тиску). Води типу I мають кластерно-полімерну структуру з об'ємними кластерами $N 6-N 20$ та їх полімерів, що надає воді особливих властивостей. Циклічні плоскі кластери $N 3-N 5$ у водах типу II за умов полімеризації здатні утворювати лише плоскі сітки, які легко формуються на поверхні води і визначають ïi поверхневий натяг. Води типу III складаються практично із димерів $\left(\mathrm{H}_{2} \mathrm{O}\right)_{2}$, які відрізняються від інших асоціатів явно вираженою схильністю до автодисоціації і визначають практично кислотно-основні властивості води: $\left(\mathrm{H}_{2} \mathrm{O}\right)_{2} \leftrightarrow \mathrm{H}_{3} \mathrm{O}^{+}+\mathrm{OH}^{-}$(спрощено: $\mathrm{H}_{2} \mathrm{O} \leftrightarrow$ $\mathrm{H}^{+}+\mathrm{OH}^{-}$). Вода IV типу має властивості звичайної полярної рідини. Взаємні переходи між різними типами вод не можуть бути різкими: вони завжди поступові, тому кожний окремий тип може мати домішки своїх “сусідів”, а у водах типу I завжди є домішки $\left(\mathrm{H}_{2} \mathrm{O}\right)_{2}$ i $\mathrm{H}_{2} \mathrm{O}$ як неминучі дефекти в конденсованій динамічній структурі.

Наведена схема структурних змін у воді під час нагрівання добре узгоджується із змінами ентропії і підтверджується екстремальним характером зростання іонного добутку води, який досягає максимальних значень при $250^{\circ} \mathrm{C}$, тобто в умовах, коли основним структурним елементом води є асоціати $\left(\mathrm{H}_{2} \mathrm{O}\right)_{2}$ [7].

$K_{\mathrm{B}}=\left[\mathrm{H}^{+}\right] \cdot\left[\mathrm{OH}^{-}\right] ; \mathrm{p} K_{\mathrm{B}}=-\log [\mathrm{H}]=11,2\left(\right.$ при $\left.20^{\circ} \mathrm{C} \mathrm{p} K_{\mathrm{B}}=14,0\right)$.

У розчинах солей структура системи буде іншою, бо частина молекул $\mathrm{H}_{2} \mathrm{O}$ зв'язується за умов гідратації іонів. Але незв’язана вода, напевно, буде структуруватися подібно до чистої.

Аналізуючи рис. 1, можна зробити певні висновки і щодо структури поверхні різних типів вод на основі температурних змін поверхнево-залежних параметрів ентропії пароутворення $(\Delta S)$ та поверхневого натягу $(\sigma)$. Величина $\Delta S$ зменшується за законом $S$-подібної кривої: до $220^{\circ} \mathrm{C}$ - із сповільненням, вище $220^{\circ} \mathrm{C}-$ із прискоренням. При $100{ }^{\circ} \mathrm{C}$ ніяких ускладнень на цій кривій не спостерігається. Отже, можна стверджувати, що у водах I і II типів поверхня має однакову молекулярну структуру, подібну до структури вод II типу. На 
Puc. 2. Схема утворення позитивно зарядженого кислого аерозолю із негативно зарядженої бульбашки газу в розчині. Знак “-” - структурно сформований заряд поверхні розчину; знаки “•” і “о” - символи іонів $\mathrm{H}^{+}$і $\mathrm{OH}^{-} .1-4-$ основні етапи процесу. Штрихова лінія - границя інтерфейсу в розчині

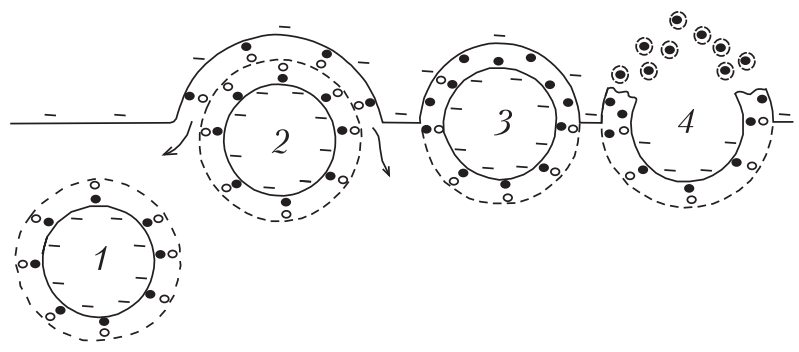

це вказує і хід кривої поверхневого натягу, яка в області вод I і II типів має нормальну параболічну форму. Все це дає підставу припускати, що у водах I типу на поверхні - в інтерфейсі газ/вода - об'ємні кластери $\left(\mathrm{H}_{2} \mathrm{O}\right)_{n}$ взагалі існувати не можуть. Хід кривих $\Delta S$ і $\sigma$ в області вод III i IV типів показує, що там структури інтерфейсів і об’ємних вод дуже близькі.

Розглянемо детальніше властивості вод типу I, до якого належать практично всі поверхневі води Землі. Термодинамічні розрахунки і комп’ютерне моделювання показали, що термодинамічна стійкість їх кластерів дуже різна: найменш стійкі напружені структури $N 6-N 8$, найстійкіші - N20 у формі пентагонального додекаедра $[4,8]$. Тому за умов нагрівання (або барботажу газів) першими завжди руйнуються малі кластери, які відповідають за розчинність $\mathrm{O}_{2}, \mathrm{~N}_{2}, \mathrm{CH}_{4}$ та інших пасивних газів. Це пояснює, чому барботаж і турбулентне механічне перемішування вод I типу викликають зменшення розчинності таких газів. Необхідно відзначити, що кластери вод типу I мають дуже багато ізомерів, які відрізняються орієнтацією молекул $\mathrm{H}_{2} \mathrm{O}$ в їх структурах. Ця обставина сильно утруднює досягнення в цих водах структурної і термодинамічної рівноваги. Тому штучно активовані стани води можуть зберігатися досить довго.

Розглянемо тепер будову інтерфейсу на межі газ/вода для вод типу I, де взаємодія молекул $\mathrm{H}_{2} \mathrm{O}$ на поверхні має односторонній характер, що зумовлює односторонню їх орієнтацію. Встановлено, що основна маса молекул $\mathrm{H}_{2} \mathrm{O}$ орієнтована там атомами кисню в сторону газової фази, а їх групи ОН зв'язані Н-зв’язками з поверхневими структурами [3]. Ефективний заряд атомів О у воді доволі високий (приблизно -0,7), тому на поверхні вони утворюють досить сильне негативне електричне поле, яке стимулює появу в рідкій фазі

\section{Зміни типів структур у чистій воді під час нагрівання (на лінії насичення)}

\begin{tabular}{|c|c|c|c|c|}
\hline \multirow{2}{*}{ Основні характеристики } & \multicolumn{4}{|c|}{ Типи структур } \\
\hline & I & II & III & IV \\
\hline Число водневих зв’язків* & 3 & 2 & 1 & 0 \\
\hline Температурний інтервал, ${ }^{\circ} \mathrm{C}$ & $0-100$ & $100-220$ & $220-340$ & $340-374$ \\
\hline Молекулярна структура асоціатів & $\begin{array}{c}\left(\mathrm{H}_{2} \mathrm{O}\right)_{n} \\
n=6-20\end{array}$ & $\begin{array}{l}\left(\mathrm{H}_{2} \mathrm{O}\right)_{m} \\
m=3-5\end{array}$ & $\left(\mathrm{H}_{2} \mathrm{O}\right)_{2}$ & $\mathrm{H}_{2} \mathrm{O}$ \\
\hline Форми асоціатів (кластерів) & Об’ємна & $\begin{array}{c}\text { Плоска } \\
\text { (циклічна) }\end{array}$ & Лінійна & - \\
\hline Схильність до полімеризації & Сильна & Середня & Слабка & Відсутня \\
\hline
\end{tabular}

* На одну молекулу $\mathrm{H}_{2} \mathrm{O}$. 


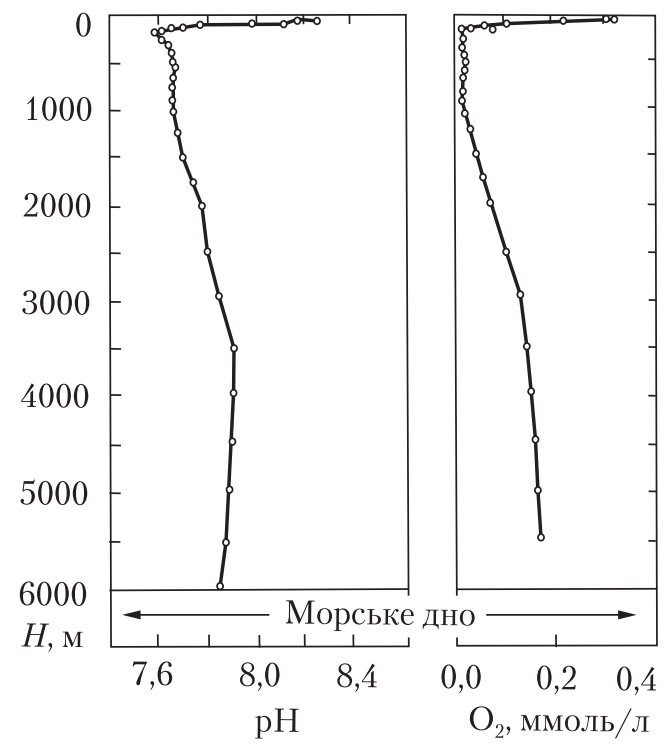

$\boldsymbol{P u c . 3 . ~ З м і н и ~} \mathrm{pH}$ і вмісту розчиненого кисню з глибиною у водах північно-східної частини Тихого океану (рис. 6.4 в [1])

подвійного електричного шару (ПЕШ) із наявних іонів. У чистій воді використовуються іони $\mathrm{H}^{+}$i $\mathrm{OH}^{-}$, у розчинах - також й іони солей. Через виштовхування аніонів із ПЕШ загальна концентрація іонів у ньому дуже низька, а розподіл їх по товщині ПЕШ нерівномірний. Тому структура води в інтерфейсі газ/вода не може збігатися із структурою в об'ємному розчині.

Враховуючи наведені результати аналізу можливих структур у воді, ми вважаємо, що в сильному електричному полі ПЕШ об'ємні кластери $\left(\mathrm{H}_{2} \mathrm{O}\right)_{n}$ дійсно існувати не можуть: вони там розпадаються на невеликі плоскі циклічні асоціати N3-N5, які належать уже до вод типу II. Тоді вода в інтерфейсі вод типу I матиме структуру вод типу II, отже, і підвищену структурну температуру. Тому у цій зоні мусить бути вищою і концентрація димерів $\left(\mathrm{H}_{2} \mathrm{O}\right)_{2}$, які надають воді більш кислого характеру. Це означає, що поверхня розчинів солей завжди має бути кислішою від об'ємного розчину. До подібного висновку прийшли і автори роботи [9] на підставі аналізу результатів своїх попередніх комп'ютерних і експериментальних досліджень. На їх думку, в інтерфейсі відбувається просторове розділення іонів $\mathrm{H}^{+}$i $\mathrm{OH}^{-}$на два різні шари: $\mathrm{H}^{+}-$ближче до поверхні, $\mathrm{OH}^{-}-$на більшій відстані. Разом ці шари фактично $\mathrm{i}$ формують ПЕШ інтерфейсу.

Описані вище властивості інтерфейсу розчинів солей дають змогу нарешті пояснити нез'ясоване досі питання: чому негативно заряджені бульбашки газу продукують при барботуванні позитивно заряджений аерозоль? Запропонована нами модель такого процесу зображена на рис. 2.

Бульбашки в розчині мають лише одну поверхню газ/вода. Заряд її поверхні негативний. Іони $\mathrm{H}^{+}$інтерфейсу притягуються до цієї поверхні, $\mathrm{OH}^{-}-$відштовхуються, тому займають нижню частину інтерфейсу. Оскільки обидва вони утворилися в результаті автодисоціації води, концентрація їх однакова і інтерфейс залишається електрично нейтральним (етап 1), а заряд бульбашки в цілому виявляється негативним. Під час виходу бульбашки на поверхню над виступаючою їх частиною виникає друга поверхня розділу газ/вода, як результат “надівання” на бульбашку частини інтерфейсу навколишнього розчину (етап 2). Під впливом сил поверхневого натягу із плівки швидко видавлюється вода дифузної частини ПЕШ, а з нею і більшість іонів $\mathrm{OH}^{-}$, які виштовхуються зовнішнім полем. Тому з часом плівка швидко зменшує свою товщину і збільшує концентрацію $\mathrm{H}^{+}$, яким зовнішнє поле не дає змоги покидати інтерфейс. Перед розривом бульбашка досягає етапу 3, коли концентрація $\mathrm{H}^{+}$у плівці набагато перевищує концентрацію $\mathrm{OH}^{-}$, отже, плівка стала кислою і позитивно зарядженою. У результаті розриву плівки (етап 4) із неї під впливом сил поверхневого натягу формуються сферичні мікроскопічні краплинки аерозолю, які відповідно до кінцевого складу плівки заряджені позитивно і мають кислотні властивості. Внаслідок 
руйнування плівки руйнується і їі поверхневий заряд; подібний заряд на краплинках аерозолю набагато менший від їх іонного заряду і тому практично стає непомітним.

Схема, зображена на рис. 2, описує лужний барботажний ефект, який виникає у випадку виносу кислого аерозолю із системи потоком газу [5]. Такий випадок реалізується на поверхні морів та океанів і відіграє, на нашу думку, важливу роль у підтримуванні лужного середовища в цих водах. Наочним підтвердженням цього висновку є картина розподілу рН по вертикалі у водах північно-східної частини Тихого океану, одержана ще 1966 р. Парком. Автор звертає увагу на подібність профілів рН і О 2 (рис. 3) та справедливо пов'язує це з біохімічним окисненням органіки, яке спричиняє появу органічних кислот або і $\mathrm{CO}_{2}$, що знижує рН. Але пояснити, чому максимум рН припадає на поверхневі води ані він, ані пізніші дослідники пояснити так і не змогли. На нашу думку, цей максимум міг виникнути тільки в результаті довготривалого лужного барботажного ефекту. Тому можна очікувати, що подібна картина буде спостерігатися в усіх океанах і великих морях.

Важливим результатом барботування повітря через морські води є збагачення морських опадів деякими елементами $\left(\mathrm{K}^{+}, \mathrm{Sr}^{2+}, \mathrm{Br}^{-}\right)$. Як показано в [4], це може бути наслідком легкого переходу в зону інтерфейсу нейтральних іонних пар, утворених в результаті сильної взаємної поляризації відповідних іонів: наприклад, $\mathrm{KBr}^{\circ}, \mathrm{SrSO}_{4}^{\circ}$. На відміну від вільних іонів, такі асоціати із зони ПЕШ виштовхуватися не будуть.

Енергія барботажного перемішування вод витрачається не тільки на утворення аерозолів, але й на підвищення структурної температури розчину i, відповідно, збільшення його хімічної активності. За нашими даними, таке барботажне активування триває близько 15 хв і приводить до виникнення особливого квазірівноважного стану з досить постійними значеннями $\mathrm{pH}$ i Eh. У розчині 0,1 $\mathrm{M} \mathrm{NaCl}$ у такому стані іони $\mathrm{H}^{+}$уже при $\mathrm{pH} 6$ легко реагують з металами середньої активності (Fe, $\mathrm{Ni}$ ), а іон $\mathrm{OH}^{-}$при рН 8 - з металами, які мають амфотерні оксидні плівки (Pb, Al). При цьому розчинений у воді кисень енергійно окиснює металічну мідь як у кислому, так і в лужному середовищі. Проте в дистильованій воді мідь при барботуванні із розчиненим киснем практично не реагує. Все це дає підставу стверджувати, що агресивність у поверхневих морських водах має бути значно більшою, ніж у глибинних.

Сукупність одержаних результатів свідчить про те, що підвищення структурної температури можливе лише у водах типу I, в яких молекулярна структура інтерфейсу не збігається із структурою об'ємної води. У водах типів II-IV такі ефекти виникати не повинні. Морські аерозолі позитивно заряджені тому, що їх вода має надлишок іонів $\mathrm{H}^{+}$і виявляє кислотний характер. Іонний заряд аерозолів виникає внаслідок розділення зарядів $\mathrm{H}^{+} \mathrm{i}$ $\mathrm{OH}^{-}$води в інтерфейсі газ/вода під впливом негативного структурного заряду на поверхні води. Подібне розділення можливе у випадку розчинених солей, якщо вони здатні утворювати в розчині достатньо стабільні нейтральні іонні пари.

\section{ЦИТОВАНА ЛІТЕРАТУРА}

1. Хорн Р. Морская химия (структура воды и химия гидросферы). Москва: Мир, 1972. 398 с.

2. Антонченко В.Я., Давыдов А.С., Ильин В.В. Основы физики воды. Киев: Наук. думка, 1991. 672 с.

3. Chaplin M. Theory VS experiment: what is the surface charge of water? Water. 2009. № 1. P. 1-28.

4. Кушнір С. Структура і властивості чистої води за різних термобаричних умов (фізико-хімічний аналіз). Мінералог. зб. 2012. № 62, вип. 2. С. 236-245. 
5. Кушнір С.В. Причини барботажного хімічного ефекту і диференціації іонів при утворенні морських аерозолів (фізико-хімічний аналіз). Допов. Нащ. акад. наук Укр. 2015. № 7. С. 91-98. doi: https://doi. org/10.15407/dopovidi2015.07.091

6. Luck W. Zur assoziation des wassers II. Salzeffekte auf die ultrarotbanden des wassers. Ber. Bunsenges. Phys. Chem. 1965. 69, № 1. S. 69-76.

7. Bandura A.V., Lvov S.N. The ionization constant of water over wide ranges of temperature and density.J. Phys. Chem. Ref. Data. 2006. 35, № 1. P. 15-30.

8. Neela Y.I., Mahadevi A. S., Sastry G.N. Hydrogen bonding in water clusters and their ionized counterparts. $J$. Phys. Chem. B. 2010. 14. P. 17162-17171.

9. Vacha R., Buch V., Milet A. et al. Autoionization at the surface of neat water: Is the top layer pH neutral, basic, or acidic? Phys. Chem. Chem. Phys. 2007. 9, № 4. P. 4736-4747.

Надійшло до редакції 11.10.2017

\section{REFERENCES}

1. Horn, R. (1972). Marine chemistry (structure of water and chemistry of hydrosphere). Moscow: Mir (in Russian).

2. Antonchenko, V. Ya., Davydov, A. S. \& Il'in, V. V. (1991). Foundations of the physics of water. Kiev: Naukova dumka (in Russian).

3. Chaplin, M. (2009). Theory VS experiment: what is the surface charge of water? Water, No. 1, pp. 1-28.

4. Kusnhir, S. (2012). Structure and properties of clear water under different thermobaric conditions (physicalchemical analysis). Mineralog. zb., No. 62, Iss. 2, pp. 236-245 (in Ukrainian).

5. Kusnhir, S. V. (2015). Reasons for the bubbling chemical effect and differentiation of ions in the formation of marine aerosols (physico-chemical analysis). Dopov. Nac. akad. nauk Ukr., No. 7, pp. 91-98 (in Ukrainian). doi: https://doi.org/10.15407/dopovidi2015.07.091

6. Luck, W. (1965). Zur assoziation des wassers II. Salzeffekte auf die ultrarotbanden des wassers. Ber. Bunsenges. Phys. Chem., 69, No. 1, pp. 69-76.

7. Bandura, A. V. \& Lvov, S. N. (2006). The ionization constant of water over wide ranges of temperature and density. J. Phys. Chem. Ref. Data., 35, No. 1, pp. 15-30.

8. Neela, Y. I., Mahadevi, A. S. \& Sastry, G. N. (2010). Hydrogen bonding in water clusters and their ionized counterparts. J. Phys. Chem. B., 114, pp. 17162-17171.

9. Vácha, R., Buch, V., Milet, A., Devlin, J.P. \& Jungwirth, P. (2007). Autoionization at the surface of neat water: Is the top layer pH neutral, basic, or acidic? Phys. Chem. Chem. Phys., 9, No. 4, pp. 4736-4747.

Received 11.10.2017

\section{С.В. Кушнир}

Институт геологии и геохимии горючих ископаемых НАН Украины, Львов

E-mail: igggk@mail.lviv.ua

\section{СТРУКТУРНАЯ ТЕМПЕРАТУРА ВОДЫ И ОБРАЗОВАНИЕ МОРСКИХ АЭРОЗОЛЕЙ (ФИЗИКО-ХИМИЧЕСКИЙ АНАЛИЗ)}

Проведен анализ физико-химических процессов, которые обусловливают образование морских аэрозолей. На основе новых данных обоснована схема четырехстадийных изменений молекулярной структуры воды при нагревании. Для холодных вод детализирована их кластерно-полимерная структура и показано, что интерфейс на границе с воздухом имеет значительно повышенную структурную температуру, которая переводит его воду из состояния I в состояние II, характерное для объемной воды при $100-220^{\circ} \mathrm{C}$. Показано, что при барботаже пассивных газов через растворы солей в воде типа I существенно возрастает структурная температура самого раствора, что приводит к уменьшению растворимости газов и повышению химической активности воды и растворенного кислорода. Предложена новая модель образования заряженного кислого аэрозоля из отрицательно заряженных пузырьков воздуха.

Ключевые слова: структура воды, структурная температура, интерфейс газ/вода, барботажная активащия воды, аэрозоли. 


\section{S.V. Kushnir}

Institute of Geology and Geochemistry of Combustible Minerals

of the NAS of Ukraine, Lviv

E-mail: igggk@mail.lviv.ua

\section{THE STRUCTURAL TEMPERATURE OF WATER AND THE FORMATION OF MARINE AEROSOLS (PHYSICO-CHEMICAL ANALYSIS)}

The analysis of physico-chemical processes that lead to the formation of marine aerosols is performed. On the basis of new data, the scheme of 4-stage changes in the molecular structure of water at the heating is substantiated. For cold water, the cluster-polymer structure is given in detail. It is shown that the interface boundary with air has a much higher structural temperature, which takes its water from state I to state II, which is characteristic of bulk water at $100-220^{\circ} \mathrm{C}$. It is shown that, at the barbotage of passive gases through solutions of salts in water I, the structural temperature of the solution substantially increases, which leads to a decrease of the solubility of gases and an increases of the chemical activity of water and dissolved oxygen. A new model of formation of a charged acidic aerosol of negatively charged air bubbles is proposed.

Keywords: water structure, structural temperature, the interface gas/water, bubbling to activate water, aerosols. 